on others. The Government had already cut by half the additional amount it agreed to pay general practitioners this year on the Review Body's recommendations. Its new restrictions for imposing the standstill are set out in three letters published in the Supplement (page 93), two from the Minister of Health and one from the Permanent Secretary to the Ministry. The Council of the B.M.A. met on Wednesday (after we went to press) to consider these letters together with resolutions from the Central Consultants and Specialists Committee, the General Medical Services Committee, and the Hospital Junior Staffs Group Executive Committee. Reports of these meetings will be published in the Supplement next week.

The Minister states in the first letter that the higher payments to hospital doctors now operative from 1 October will be made at the beginning of January 1967. For general practitioners the effective date for the first phase of the increased remuneration, which was formerly 1 April 1966, will now be 1 October, and payment will be made at the beginning of January 1967 ; but the effective date of certain smaller items which were formerly to become payable from 1 October will now be deferred until 1 April 1967. While the Government's intention is that net remuneration shall remain unchanged in the standstill the Minister states in his second letter that special arrangements will have to be made for general practitioners for the period 1 April to 30 September 1966. The intention of these will be that " proper allowance is made for the higher level of expenses assumed by the Review Body to be incurred in this period." In addition, if general practitioners have incurred additional expenses for ancillary staff since 4 May 1966 in anticipation of the Review Body's award being put into effect from 1 April the Government is prepared to make some recompense. The nature of its undertaking and the manner in which it proposes to fulfil it are set out in the second letter from the Minister. A third letter, that from the Permanent Secretary, indicates that general practitioners should not, as a result of the standstill, be out of pocket from this cause. Clearly complex arrangements of this kind would have to be closely watched to see that they work satisfactorily in the great variety of individual circumstances. The same letter also opens the door to discussions apparently of a more general nature in cases "where a legitimate increase in expenses made in the light of acceptance of the Review Body's report might, as a result of the stabilization of gross fees, lead to a fall in net income if no special arrangements were made."

The provision of first-class health services, whether in hospital and general practice, in public health, or in other branches of the profession, is a political aim common to all parties. The country wants to have these services and doctors want to provide them. But no Government has yet had the courage to tell the country what an unrestricted service means in terms of cost. Nor did the present Government show a realistic approach to the running of the N.H.S. when by removing the charge on prescriptions it added further burdens to general practice and $£ 50 \mathrm{~m}$. a year to the nation's bill.

The Government's actions over the Review Body's recommendations have gravely harmed confidence between the profession and itself. If the present standstill is not to damage an already under-financed Health Service beyond repair, it must be shown to be an inescapable national duty to back it up. The obligations it imposes must be equitable and the sacrifices equally shared. In that spirit medical men and women, like any other section of the community, will be ready to play their part in rescuing the country from its plight.

\section{Fungi in Nails}

Fungal infection of the rails is quite common, and seems to be getting more common. The number of patients with tinea unguium has increased greatly in the last ten years. Margaret M. Walshe and Mary P. English ${ }^{1}$ have recently reported the results of their surveys of fungal infection of the nails. All abnormal toenails seen in one dermatological clinic were examined for the presence of fungi, and an incidence of fungal infection of $47 \%$ was found. Walsh and English also reported the incidence of fungal species in clippings from finger and toenails sent for mycological diagnosis. Dermatophyte infections were found four times more frequently in toenails than in fingernails, and Trichophyton rubrum was the most common fungus. In contrast, species of candida were found in fingernails 16 times more often than in toenails.

On clinical examination infected nails may be seen to be deformed in a number of ways. With trichophyton infections scaling between or around the toes may be present, the nail plate becomes brown, soft, and broken, and it is often thickened. Psoriasis may produce a similar appearance and may present difficulty in differential diagnosis unless skin lesions are present, though the two conditions may occur together. Sometimes the whole nail plate becomes white. Small haemorrhages may be visible through the nail and occasionally it separates from its bed (onycholysis) or there may be heaping up of keratin under the plate. Infection of nails with Candida albicans is usually a complication of chronic paronychia and may produce dystrophy very similar to that caused by trichophyton infection.

A firm mycological diagnosis must be made before treatment, for trichophyton infections can be cured by griseofulvin, but this drug has no effect on C. albicans. P. D. Samman ${ }^{2}$ recommends that a large dose of griseofulvin should be used for the first two weeks, and suggests eight $125 \mathrm{mg}$. tablets daily for adults of $160 \mathrm{lb}$. (72.5 kg.) or over. The dose should then be reduced to six tablets a day for two to four weeks, after which the patient should take four tablets a day until he is cured. The slow growth of nails makes this period about six months for fingernails and even more for toenails, so that it is best to remove infected toenails after a few weeks of treatment, which should then be continued until the new nail appears to be healthy. Griseofulvin does not control skin infection and this should be treated with benzoic acid compound ointment (B.P.C.).

The treatment of infections of nail plate with $C$. albicans is unsatisfactory. If there is chronic paronychia treatment should be given with nystatin ointment or amphotericin B lotion. The nail may then grow from the nail fold uninfected and after about six months become normal. It may occasionally be necessary to remove the infected nail. 